\title{
Become Immediate of Newborns Operated in the Neonatology Department of the Hospital and University Center Gabriel Toure of Bamako (Mali)
}

\author{
Oumar Coulibaly ${ }^{1 *}$, Hawa Gouro Diall ${ }^{1}$, Pierre Togo ${ }^{1}$, Hawa Camara ${ }^{1}$, \\ Fatoumata Léonie Françoise Diakité1, Lala Ndrayni Sidibé1, Leyla Maiga1, Ibrahima Ahamadou1, \\ Abdoul Karim Doumbia' ${ }^{1}$, Adama Dembelé1, Belco Maiga', Karamoko Sacko', \\ Mohamed Elmouloud Cissé1, Djeneba Konaté1, Fousseyni Traoré1, Yacouba Aba Coulibaly1, \\ Issa Amadou Touré2, Hamadi Sissoko ${ }^{3}$, Mariam Maiga ${ }^{4}$, Alou Samake4, Bourama Kané5, \\ Guédiouma Dembelé5, Abdoul Aziz Diakité1, Fatoumata Dicko Traoré1, Mariam Sylla1, \\ Boubacar Togo ${ }^{1}$
}

\author{
${ }^{1}$ Neonatology Department of the Gabriel Touré CHU, Bamako, Mali \\ ${ }^{2}$ Pediatric Surgery Department of the Gabriel Touré CHU, Bamako, Mali \\ ${ }^{3}$ Reference Health Center of the Municipality III, Bamako, Mali \\ ${ }^{4}$ Reference Health Center of the Municipality VI, Bamako, Mali \\ ${ }^{5}$ Mali Hospital, Bamako, Mali \\ Email: *cheickcoul1@live.fr
}

How to cite this paper: Coulibaly, O., Diall, H.G., Togo, P., Camara, H., Diakité, F.L.F., Sidibé, L.N., Maiga, L., Ahamadou, I., Doumbia, A.K., Dembelé, A., Maiga, B., Sacko, K., Cissé, M.E., Konaté, D., Traoré, F., Coulibaly, Y.A., Touré, I.A., Sissoko, H., Maiga, M., Samake, A., Kané, B., Dembelé, G., Diakité, A.A., Traoré, F.D., Sylla, M. and Togo, B. (2022) Become Immediate of Newborns Operated in the Neonatology Department of the Hospital and University Center Gabriel Toure of Bamako (Mali). Open Journal of Pediatrics, 12, 12-18. https://doi.org/10.4236/ojped.2022.121002

Received: November 22, 2021 Accepted: January 11, 2022 Published: January 14, 2022

\begin{abstract}
Neonatal surgical pathologies in developing countries are characterized by high mortality. The aim of this work was to describe the characteristics of the newborn and its surgical pathologies treated in the neonatal department of the Gabriel Touré University Hospital in Bamako (Mali). Patients and method: This is a retrospective study of 626 files of newborns hospitalized over a period of 3 years (January 2016 to December 2018) for a surgical pathology, whether operated on or not. We have studied the etiological, therapeutic and evolutionary aspects. Results: During the study period, we collected 626 patients who had surgical pathology, i.e. a frequency of $5.35 \%$. The average therapeutic consultation time was 2 days with extremes ( 1 and 30 days). Pathologies of the abdominal wall and digestive tract represented $57.9 \%(n=84)$ followed by pathologies of the spine $26.9 \%(n=39)$. The mean treatment time was 4.5 days. Twenty-three point sixteen $(23.16 \%)$ newborns could be operated on. The neonatal mortality rate was $12.4 \%(\mathrm{n}=18)$. Mortality was postoperative $(100 \%)$ with a mean time to onset of 5 days. Abdominal wall pathologies were responsible for $8.7 \%(n=13)$ of deaths. Conclusion: Surgical pathologies of the newborn are characterized by delayed treatment with high
\end{abstract}


Copyright $\odot 2022$ by author(s) and Scientific Research Publishing Inc. This work is licensed under the Creative Commons Attribution International License (CC BY 4.0).

http://creativecommons.org/licenses/by/4.0/ mortality. Improving their prognosis requires early diagnosis (prenatal diagnosis) and adequate management.

\section{Keywords}

Newborn, Surgical Pathologies, Mortality

\section{Introduction}

Neonatal surgical pathologies are frequent causes of neonatal morbidity and mortality [1]. Neonatal surgical pathologies are structural anomalies or abnormal functions that appear from birth to the end of the first month of life and require urgent surgical treatment [1] [2]. It is most often a surgical emergency involving the vital and/or functional prognosis. While in industrialized countries life expectancy has improved thanks to prenatal diagnosis, in developing countries there are several difficulties in managing it [2] [3]. In Africa, they are thought to be the reason for around $10 \%$ of surgical interventions in the various pediatric surgical services [3] [4]. Neonatal surgical emergencies represented $19.8 \%$ of admissions to the pediatric surgery department of the Yopougon University Hospital in Abidjan, Côte d'Ivoire [5] and 12.8\% of those to the Pediatric Surgery department of the Lamordé National Hospital in Niamey in Niger [6]. In some contexts, newborns are cared for in general surgery departments. This is the case in Bukavu in the Democratic Republic of Congo, where surgical pathology of the newborn represents $1.31 \%$ of surgical pathology [7]. In Bamako in Mali, the neonatal and pediatric surgery services, the last level of national reference structures, provide synergistic management of neonatal surgical pathologies. The aim of this study was to identify neonatal surgical pathologies and to analyze their prognosis in our environment.

\section{Patients and Method}

This was a retrospective study to aim for descriptive carried out in the neonatology department of the Gabriel Touré Hospital and University Center in Bamako, between January 2016 and December 2018, i.e. in 3 years. All newborns aged 0 to 28 days hospitalized for a life-threatening or non-life-threatening surgical pathology and whose records were usable constituted our study population. For each patient, the parameters studied were: age at admission, place of origin, means of evacuation, consultation time, weight on admission, diagnostic time, different pathologies, time therapeutic (defined as the time between indication and surgery) and mortality. Data were entered and analyzed using Epi info software version 7.2.

\section{Results}

Of the 11,697 hospitalizations during the study period, 626 cases of surgical pa- 
thology were retained and 145 received surgery. The frequency of neonatal surgical pathologies was $5.35 \%$. These were 85 boys and 60 girls (sex ratio: 1.4). The mean age at admission was an extreme 2.9 days ( 0 and 26 days). Thirty-five cases (24.2\%) came from a primary structure, 57 cases (39.3\%) from a secondary structure, 35 cases $(24.2 \%)$ from a tertiary structure and 18 cases $(12,4 \%)$ from home. The average weight at admission was extreme $2281 \mathrm{~g}$ (1300 and 4100g). The reasons for consultation were dominated by spina bifida (26.9\%) followed by anal imperforation (25.5\%), Table 1 . The mean time to consultation was extreme 1.7 days ( 0 and 30 days). The diagnosis of the various pathologies was made either from the referent structure or in our department with an average diagnostic delay of 3 extreme days ( 24 hours and 6 days). Antenatal diagnosis was made in 2 cases (1.4\%). Pathologies of the digestive tract and abdominal wall accounted for $57.9 \%(n=84)$ followed by pathologies of the spine $26.9 \%(n=$ 39). These different pathologies were summarized in Figure 1. Surgical management involved 145 newborns (23.16\%). The mean treatment time was 4.5 days with extremes ( 1 and 26 days). The associated malformations were dominated by microcephaly (10.3\%) followed by poly-malformation syndrome $(6.9 \%)$ (Figure 2). Intraoperative complications were $6.2 \%(\mathrm{n}=9)$ dominated by hemorrhage (3.4\%), cardiopulmonary arrest $(2.1 \%)$ and respiratory distress $(0.7 \%)$. The overall mortality in our series was 18 cases (12.4\%), all postoperatively. These deaths had an average delay of 12.4 extreme days (D1 to D48). Deaths occurred in a picture of severe infection and/or sepsis in $66.7 \%(\mathrm{n}=12)$ and

Table 1. Distribution of newborns according to the reason for consultation.

\begin{tabular}{ccc}
\hline Reason for consultation & effective & percentage \\
\hline Spina bifida & 39 & 26.9 \\
Omphalocele & 37 & 25.5 \\
Anal imperforation & 28 & 19.3 \\
Abdominal distension & 10 & 6.9 \\
Abdominal distension + INN & 7 & 4.8 \\
Malformation syndrome & 5 & 3.4 \\
Hydrocephalus & 6 & 4.1 \\
Bladder extrophy & 4 & 2.8 \\
Congenital malformation & 2 & 1.4 \\
Laparoschisis & 4 & 2.8 \\
Macrocephaly & 1 & 0.7 \\
Strangulated inguinal hernia & 1 & 0.7 \\
Abdominal malformation & 1 & 0.7 \\
Total & 145 & 100 \\
\hline
\end{tabular}

Spina Bifida, omphalocele and anal imperforation were the main reasons for consultation. 

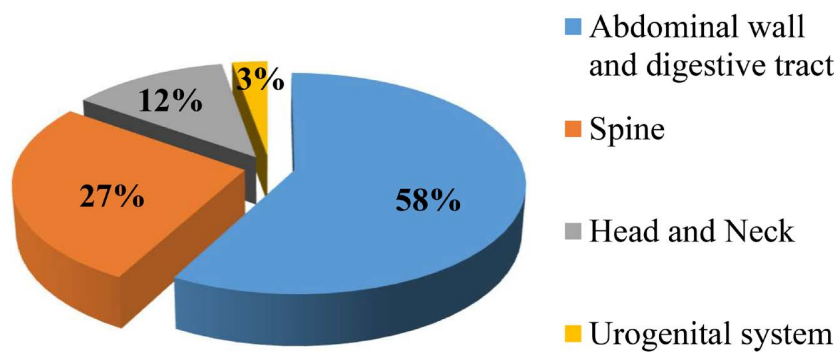

Figure 1. Distribution of pathologies by site (The abdominal wall and the digestive tract, followed by the spine were the main locations of surgical pathologies).

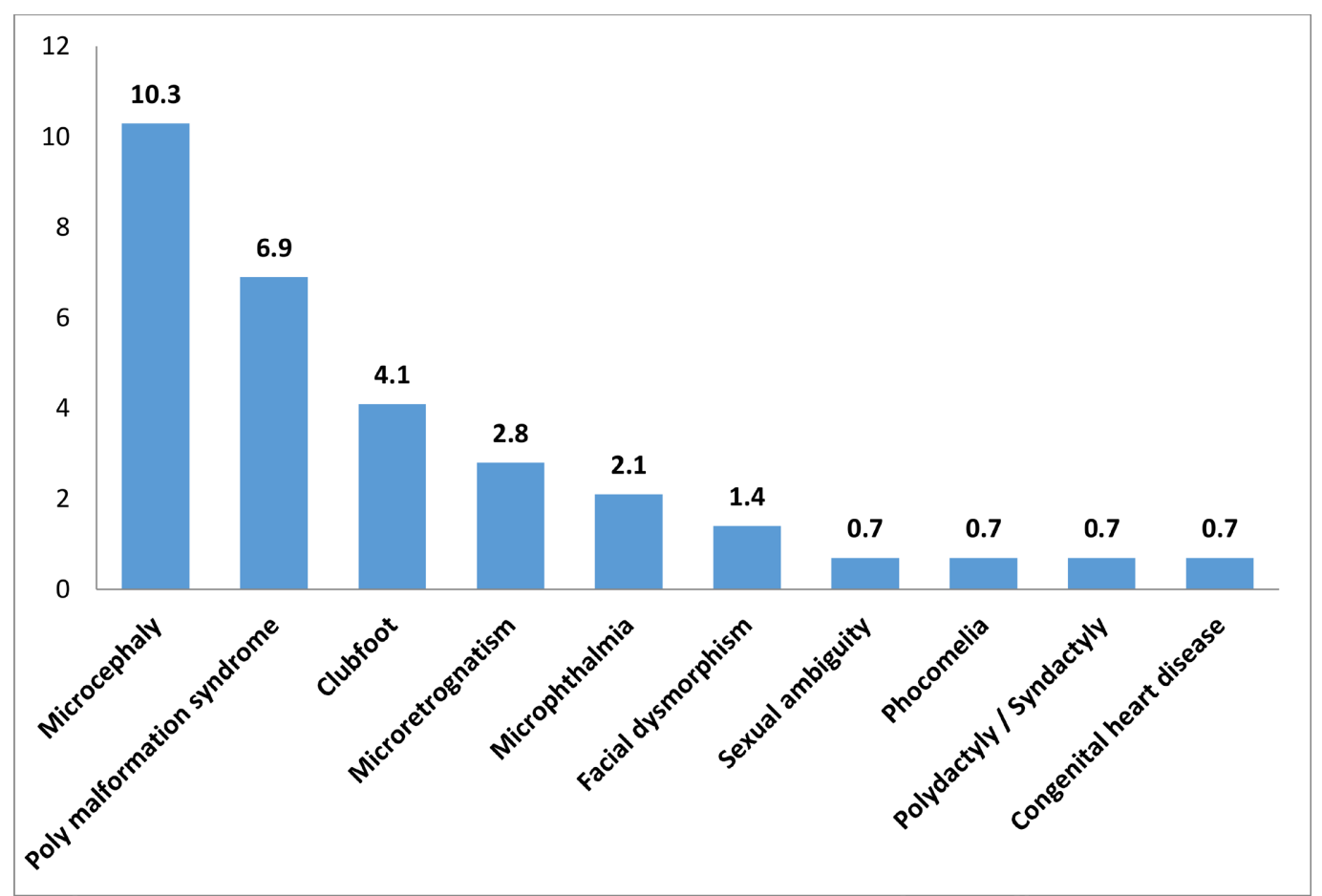

Figure 2. Distribution of newborns according to associated malformations (Microcephaly and poly-malformation syndrome were the main associated malformations).

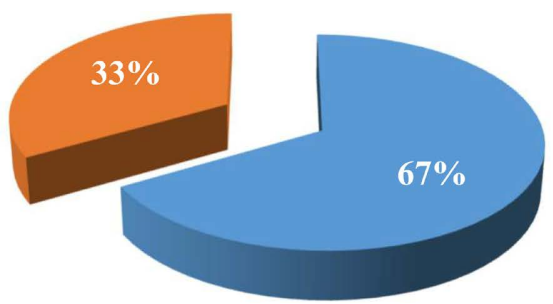

- Severe infection / sepsis

- Hemodynamic shock

Figure 3. Distribution according to the causes of death of operated newborns (Severe infection/sepsis and hemodynamic shock were the leading causes of death).

hemodynamic shock in $33.3 \%(\mathrm{n}=8)$. The distribution of mortality by pathology was summarized in Figure 3.

\section{Discussion}

The aim of this work was to describe the characteristics of the newborn and its 
surgical pathologies treated in the neonatal department of the CHU Gabriel Touré in Bamako.

The limitations of this study are inherent in its retrospective nature. However, this study allows us to have an overview of this pathology in the absence of related data. Neonatal surgical pathologies represented 5.35\% of admissions to our department with an annual incidence of 48.3 newborns. Our frequency is close to that of Natacha B in Libreville, higher than that of Fabrice C. G in Congo [7] [8]. In African series, neonatal surgical pathologies represented $9.7 \%$ to $61 \%$ of admissions [5] [9]. In Indian and British series this incidence was higher than ours, 60 to 301 newborns per year [10] [11]. The demographic characteristics of the populations and the specificities of the pediatric surgical services which cover them are variable and determine the hospital incidence. The mean age in our study was 2.9 days. In African and Indian series, we found average ages greater than ours ranging from 5 to 8 days [3] [5] [6] [9]. The majority of newborns were 0 to 7 days old on admission to our study (89.7\%). In the studies by Badrinath et al. in Uganda, and Omid col. in Niger, the majority of patients were also admitted during the first week of life with $63.5 \%$ and $60.2 \%$ of cases, respectively parents to see their child early and urgently [6] [9]. In our series, as in the literature, we note a male predominance: respectively $58.5 \%$ of boys and between $56 \%$ and 75\% of male newborns [6] [7] [9] [12]. On the other hand, in the series of Mieret J. C, in Yopougon and Natacha B in Libreville, [5] [8], the female sex was predominant. There is no clear consensus on the predominance of a genre.

The most common diagnosis in our study was anorectal malformations, 37.9\% $(\mathrm{n}=55)$, followed by myelomeningocele, $26.9 \%(\mathrm{n}=39)$ and anterior abdominal wall defects: omphalocele and laparoschisis, 22.1\% $(\mathrm{n}=32)$. In other African studies [4] [6] [9], anorectal malformations were the most frequently found pathology: varying between $9.5 \%$ and $39 \%$ of cases. In a meta-analysis of neonatal surgery in Africa (51 studies) intestinal atresia was observed in $54.9 \%$ of the work, anterior abdominal wall defect in $52.9 \%$ of studies and anorectal malformations in $47.1 \%$ of the Ekenze series, in 2016 [3]. As a result, Natacha et al. in Libreville found a predominance of digestive disorders, $47.6 \%$ followed by anomalies of the anterior wall of the abdomen, $26.2 \%$ [8]. The spectrum of neonatal surgical admissions may vary from hospital to hospital depending on the availability of prenatal diagnostic facilities, transport facilities and presentation time.

The newborns in our series were operated less frequently $(23.16 \%)$ than in other studies: from $28.3 \%$ to $67.7 \%$ of operated newborns [5] [6] [8] [9] [12]. Variations in the proportions between pathologies requiring emergency surgery (colostomy for anaorectal malformation for example) and those for which conservative treatment is possible (such as omphalocele) could explain such a difference.

Mortality is in most studies higher than ours (12.4\%) varying from $25.8 \%$ to 61.1\%) [5] [6] [7] [8]. Advances in diagnostic techniques and perioperative care 
have greatly improved the therapeutic results of neonatal surgery. Despite everything, there are disparities in terms of the results of neonatal surgery between countries with high income and those with average or low income [3]. According to a meta-analysis this is due to late presentation and inadequate facilities in 39 studies (76.5\%), lack of trained support staff in 32 series (62.7\%) and lack of intensive care neonates in 29 studies (56.9\%) (Ekenze, 2016) [3].

The morbidity and mortality factors identified in various studies were: delay in diagnosis (which could be explained by the lack of antenatal diagnosis) and management, prematurity and low birth weight, impairment of digestive system, unsafe transport, cultural factors (beliefs and customs), anesthetic complications and the presence of multiple congenital anomalies) [6] [7] [8] [12] [13].

The intraoperative complications in our study were managed by filling, transfusion, and respiratory support. Postoperative mortality in our study was $100 \%$ $(\mathrm{n}=18)$. In developing countries, postoperative mortality is still very high, varying from $8.7 \%$ to $62.3 \%$ [5] [6] [9] [14]. This variation in mortality could be linked, among other things, to the size of the samples and the type of structure where the study was carried out. Mortality in our patients was mostly early mortality: $38.9 \%$ of deaths (7 cases). Many other African authors have found this predominance of deaths during the first week with respectively $43.5 \%, 58.2 \%$, $68 \%$ and $70 \%$ of cases [5] [6] [9] [14].

Deaths occurred primarily in cases of anorectal malformations (33.3\%) in our series. This observation is valid in the series by Ralahy in 2010 (28\%) [15]. On the other hand, Mieret in Ivory Coast and Omid in Niger found a predominance of omphaloceles for deaths (34.21\% and 26\%) [5] [6].

\section{Conclusion}

Neonatal surgical emergencies are relatively frequent in our study. They are characterized by a delay in diagnosis and treatment, burdened by high mortality in developing countries. Improving the prognosis of newborn surgical emergencies requires diagnosis (antenatal diagnosis) and early management, the appropriate technical platform and the creation of a neonatal intensive care unit would reduce this mortality rate.

\section{Conflicts of Interest}

The authors declare no conflicts of interest regarding the publication of this paper.

\section{References}

[1] WHO (2015) Birth Defects Surveillance Training: Facilitator's Guide. World Health Organization, Geneva, 1-162.

[2] Taguchi, T., Nagata, K., Kinoshita, Y. and Esumi, G. (2014) Progress in and Outcomes of Neonatal Surgery over the Past 50 Years. Nihon Geka Gakkai Zasshi, 115, 306-311.

[3] Ekenze, S.O., Ajuzieogu, O.V. and Nwomeh, B.C. (2016) Challenges of Manage- 
ment and Outcome of Neonatal Surgery in Africa: A Systematic Review. Pediatric Surgery International, 32, 291-299. https://doi.org/10.1007/s00383-016-3861-X

[4] Chirdan, L.B., Ngiloi, P.J. and Elhaby, E.A. (2012) Neonatal Surgery in Africa. Seminars in Pediatric Surgery, 21, 151-159. https://doi.org/10.1053/j.sempedsurg.2012.01.007

[5] Mieret, J.C., Kouamé Yapo, G.S., Yaokreh, J.B. and Dieth, A.G. (2014) Prognosis of Neonatal Surgical Pathologies at the Yopougon University Hospital. Revue International des Sciences Médicales, 16, 126-129.

[6] Omid, A.A.M., Hellé, M., Habou, O., Chérif Maiguizo, A.K. and Habarchi, H. (2017) Neonatal Surgical Pathologies at the Lamordé National Hospital in Niamey: Diagnostic, Therapeutic and Prognostic Aspects. European Scientific Journal, 13, 156. https://doi.org/10.19044/esj.2017.v13n24p156

[7] Fabrice, C.G., Kabakuli, A.N. and Ndechu, A.B. (2016) Neonatal Surgical Emergencies at the Bukavu Provincial General Reference Hospital in Democratic Republic of Congo. The Pan African Medical Journal, 24, Article No. 219.

[8] Boumas, N., Minko, J.I., Mba Ella, R. and Mba Meyo, J. (2017) Epidemiological Profile of Neonatal Surgical Emergencies of Libreville CHU. Bulletin Médical d Owendo, 15, 17-20.

[9] Badrinath, R., Kakembo, N., Kissa, P., Langer, M., Ozgediz, D. and Sekabira, J. (2014) Outcomes and Unmet Need for Neonatal Surgery in a Resource Limited Environment: Estimates of Global Health Disparities from Kampala Uganda. Journal of Pediatric Surgery, 49, 1825-1830. https://doi.org/10.1016/j.jpedsurg.2014.09.031

[10] Burge, D.M. and Drewett, M. (2012) Workload and Costs Associated with Providing a Neonatal Surgery Service. Archives of Disease in Childhood. Fetal and Neonatal Edition, 97, 179-181. https://doi.org/10.1136/archdischild-2011-300094

[11] Bhatnagar, S.N. and Sarin, Y.K. (2012) Current Trends in Neonatal Surgery in India. Journal of Neonatal Surgery, 1, 18-21.

[12] Awad, R.A. and Karasani, S.H. (2014) Pattern of Neonatal Surgical Presentation and Outcome in Sinnar Hospital (2013-2014). Global Journal of Medical Research, 14, $17-22$.

[13] Ugwu, R.O. and Okoro, P.E. (2013) Pattern Outcome and Challenges of Neonatal Surgical Cases in a Tertiary Teaching Hospital. African Journal of Paediatric Surgery, 10, 226-230. https://doi.org/10.4103/0189-6725.120886

[14] Ndour, O., Fall, F.A., Alumeti, D., et al. (2009) Factors of Neonatal Mortality in the Pediatric Surgery Department of the Aristide Le Dantec University Hospital in Dakar. Mali Medical, 14, 33-38.

[15] Ralahy, M.F., Rakotoarivoni Rabenasolo, S.T., Rakotovao, M.A., Hunaald, F.A. and Andriamanarivo, M.L. (2010) Neonatal Mortality in the Emergency Department of the CHUA-JRA Antananarivo-Madagascar. Emergency Medical Anesthesia Review, 2, 15-17. 